\title{
PENGUKURAN KINERJA PUSKESMAS DALAM RANGKA PENINGKATAN LAYANAN KESEHATAN MASYARAKAT
}

\author{
Dhidik Apriyanto \\ Jurusan Ilmu Administrasi FISIP Universitas Tanjungpura \\ Pontianak Kalimantan Barat \\ email: dhidikapriyanto@gmail.com
}

\begin{abstract}
This reseach is an attempt to measure how the performance of health center services at Parit Haji Husein II Pontianak in order to improve public health services. The analysis tool used is a statistical method to determine the Cartesian diagram where the gap of each answer the questionnaire. While the variables used are five dimensions of service quality developed by Parasuraman et.al, with the acronym RATER namely Reliability, Assurance, Tangible, Empaty, and Responsiveness.

The results of the analysis of Cartesian diagram of the five variables are: item questions coming in the position I was Diagnosis doctor precise and accurate, Caution patient satisfaction, skills of employees in the airport, Courtesy of services, Analysis Physicians who do not doubt, Analysis doctor is not at risk, doctors can be trusted Easy, consult a physician and employee, there is no obstacle in consultation with a doctor, Doctor with your info detail, doctor requested information to the patient about the complaint, Doctor responsive, Diagnosis physician accountable, Doctor listened well, doctor serving patients during hours work. While the services that go into quadrant II on the Compliance schedule open and close. And service entry in quadrant III is the speed of service, employee came right on time, good physical form health center, health center facilities complete, ready at the desk clerks, Means technology is already good, adequate waiting room chair. While the service entrance in quadrant $I V$ is a doctor and staff give direction well and say hello to the visitor confused.
\end{abstract}

Keywords : measurement, performance, service, health centers, Cartesian diagram.

\begin{abstract}
ABSTRAK
Penelitian ini merupakan usaha untuk mengukur bagaimana kinerja pelayanan Puskesmas Parit Haji Husein II Pontianak dalam rangka peningkatan layanan kesehatan masyarakat. Alat analisis yang digunakan adalah metode statistik Diagram Kartesius dimana untuk mengetahui gap dari setiap jawaban kuesioner. Sedangkan variable yang digunakan adalah lima dimensi kualitas layanan yang dikembangkan oleh Parasuraman et.al, dengan akronim RATER yaitu Reliability, Assurance, Tangible, Empaty, dan Responsiveness.

Hasil analisis Diagram Kartesius dari kelima variable tersebut adalah: item pertanyaan yang masuk pada posisi I adalah Diagnosa dokter tepat dan Akurat, Perhatian kepuasan pasien, Kecakapan pegawai dalam melayani, Kesopanan pelayanan, Analisis Dokter yg tidak meragukan, Analisis Dokter tidak beresiko, Dokter dapat dipercaya, Mudah berkonsultasi dengan dokter dan pegawai, Tidak ada hambatan konsultasi dengan dokter, Dokter memberi info dengan detail, Dokter minta info ke pasien tentang keluhan, Dokter cepat tanggap, Diagnosa Dokter dapat dipertanggung jawabkan, Dokter mendengarkan keluhan dengan baik, Dokter melayani pasien selama jam kerja. Sedangkan layanan yang masuk ke kuadran II yaitu Kesesuaian jadwal buka dan tutup. Dan layanan yang masuk pada kuadran III adalah Kecepatan pelayanan, Pegawai datang tepat waktu, Bentuk fisik puskesmas bagus, Fasilitas puskesmas lengkap, Pegawai siap di meja, Sarana teknologi sudah baik, Kursi ruang tunggu memadai. Sedangkan layanan yang masuk di kuadran IV adalah Dokter dan pegawai memberikan arahan dengan baik dan Petugas menyapa kepada yang bingung.
\end{abstract}

Kata kunci: pengukuran, kinerja, layanan, puskesmas, diagram kartesius 


\section{PENDAHULUAN}

Dalam era globalisasi sekarang ini perkembangan sektor jasa semakin bertambah penting dalam usaha peningkatan kesejahteraan dan kesehatan masyarakat. Perkembangan sektor jasa tersebut didorong oleh kemajuan pesat dalam bidang teknologi. Tuntutan masyarakat terhadap peningkatan kualitas pelayanan semakin dirasakan penting karena masyarakat semakin kritis terhadap produk jasa yang diperolehnya. Masyarakat sebagai konsumen tidak lagi sekedar membeli suatu produk jasa tetapi juga lebih menginginkan suatu pelayanan yang terjamin dan berkualitas dari pra pembelian sampai tahap purna pembelian. Pelayanan yang baik dan prima akan berdampak pada terciptanya kepuasan masyarakat terhadap jasa yang diperoleh oleh masyarakat itu sendiri dan juga akan meningkatkan kepercayaan masyarakat terhadap kinerja suatu instansi tersebut.

Penyelenggaraan negara mempunyai peran yang sangat menentukan terhadap keberhasilan pelaksanaan tugas umum pemerintahan, pembangunan dan tugas- tugas pelayanan kepada masyarakat dalam mewujudkan tujuan dan sasaran pembangunan nasional yang berkesinambungan. Aparatur Negara diharapkan dapat menjalankan fungsi pelayanan secara professional, berdaya guna, produktif, transparan, bebas dari korupsi, kolusi dan nepotisme untuk melaksanakan dan mewujudkan kepemimpinan yang baik (good governance).

Pemerintah diharapkan dapat memberikan perubahan yang positif ke arah peningkatan terhadap pelayanan kepada masyarakat terutama yang berkaitan dengan tugas- tugas pelayanan masyarakat. Lembaga pelayanan masyarakat baik yang profit maupun non profit harus dapat lebih menunjukkan perannya dalam melayani kebutuhan masyarakat melalui peningkatan kualitas pelayanan. Lembaga pelayanan yang dapat memberikan layanan yang terbaik kepada masyarakat maka akan lebih mudah dalam meraih konsumen.

Sebaliknya, jika lembaga tersebut tidak mampu melayani konsumen dengan baik, maka akan ditinggalkan oleh konsumen ataupun kepercayaan masyarakat akan kinerja lembaga tersebut akan berkurang. Jasa pelayanan yang baik dan prima akan dirasakan oleh masyarakat apabila instansi tersebut benar- benar dapat melayani secara santun dan professional dengan prosedur yang sederhana, lancar, aman, tertib, ada kepastian biaya dan waktu, serta hukum atas jasa pelayanan yang diberikan. Seiring dengan perkembangan zaman yang semakin maju, perkembangan sektor jasa semakin penting guna menuju peningkatan kesejahteraan masyarakat khususnya dalam hal pelayanan kesehatan. Hal tersebut didukung oleh adanya perkembangan teknologi yang semakin modern di segala bidang kehidupan. Peningkatan kualitas layanan kesehatan pun dirasa semakin penting.

Masyarakat dewasa ini semakin selektif untuk mendapatkan pelayanan kesehatan yang berkualitas, mereka sebagai pengguna jasa, tidak hanya membayar namun menuntut pelayanan yang baik dan berkualitas mulai di awal hinggga akhir. Masyarakat akan merasakan kepuasan apabila menerima pelayanan yang baik dan profesional dari penyedia pelayanan. Jika mereka memperoleh kepuasan atas layanan yang diberikan, maka akan timbul kepercayaan dari masyarakat sebagai pengguna jasa untuk menggunakan kembali layanan tersebut. Penyedia pelayanan kesehatan di tingkat pertama adalah pusat kesehatan masyarakat (Puskesmas). Puskesmas merupakan unit pelaksana pelayanan kesehatan di wilayah kecamatan. Pembangunan puskesmas di tingkat kecamatan memiliki peran yang sangat penting dalam memelihara kesehatan masyarakat. Apabila berfungsi dengan baik, maka akan mampu memberikan pelayanan yang bermutu bagi masyarakat yang membutuhkan puskesmas. Puskesmas merupakan ujung tombak berhasil tidaknya pembangunan kesehatan di lingkungan 
kecamatan. Pembangunan kesehatan merupakan upaya memenuhi salah satu hak dasar rakyat, yaitu hak rakyat untuk memperoleh akses atas kebutuhan pelayanan kesehatan. Pembangunan kesehatan juga dipandang sebagai suatu investasi dalam kaitannya untuk mendukung peningkatan kualitas sumber daya manusia dan pembangunan ekonomi, serta memiliki peran penting dalam upaya penanggulangan kemiskinan, karena pembangunan hanya dapat berjalan apabila dilakukan oleh manusia yang sehat.

Kesehatan sebagai investasi karena hanya manusia sehat lahir dan batin yang mampu berperan dalam pembangunan, telah disadari oleh masyarakat namun komitmen untuk melaksanakan kurang tampak. Kesenjangan antara kaya dan miskin serta ketidakadilan sosial masih tampak jelas. Masyarakat kelas atas tidak akan kesulitan untuk mendapatkan pelayanan kesehatan yang baik karena mereka mempunyai kekayaan untuk pembiayaan kesehatan mereka. Sedangkan mereka yang berada di masyarakat kelas bawah untuk biaya kehidupan sehari- sehari saja masih kekurangan apalagi untuk mendapatkan pelayanan kesehatan yang baik pastilah akan mengalami kesulitan.

Seiring pembenahan-pembenahan yang dilakukan membuat semua kalangan masyarakat tidak canggung lagi menggunakan layanan puskesmas. Hal ini didukung dengan kondisi Puskesmas yang jauh lebih baik, yaitu dengan gedung yang baru, sarana prasarana lebih lengkap dan pembenahan sistem pelayanan.

\section{TINJAUAN TEORI}

Pelayanan yang unggul adalah suatu sikap atau cara karyawan dalam melayani pelanggan secara memuaskan (Elhaitammy dalam Tjiptono, 1996). Dalam hal ini terdapat empat unsur pokok dalam kualitas jasa (pelayanan), yaitu kecepatan, ketepatan, keramahan, dan kenyamanan. Keempat komponen tersebut merupakan satu kesatuan yang utuh. Artinya jika salah satu dari empat unsur tersebut kurang atau tidak ada, maka kualitas pelayanan menjadi tidak unggul. Untuk itu, agar dicapai tingkat kualitas pelayanan yang unggu, setiap karyawan harus memiliki ketrampilan tertentu. Seperti berpenampilan yang baik dan sopan, bersikap ramah, bergairah kerja menguasai tugas dan pekerjaannya/bertindak profesional, mampu berkomunikasi dengan baik, dan seterusnya. Dengan demikian, baik tidaknya suatu jasa/pelayanan tergantung dari kualitas total dari suatu jasa yang diberikan. Menurut Gronroos (dalam Tjiptono, 1996), kualitas total surat jasa terdiri dari tiga komponen utama, yaitu :

1. Technical Quality, yaitu komponen yang berkaitan dengan kualitas keluaran (output) jasa yang diterima pelanggan. Technical Quality dapat diperinci menjadi:

a. Search Quality, yaitu kualitas yang dapat dievaluasi oleh pelanggan sebelum membeli. Contoh: harga.

b. Experience Quality, yaitu kualitas yang hanya dapat dievaluasi pelanggan setelah membeli atau mengkonsumsi jasa. Contoh: ketepatan waktu, kecepatan layanan, dan kerapian hasil.

c. Credence Quality, yaitu kualitas yang sukar dievaluasi pelanggan meskipun telah mengkonsumsi suatu jasa. Contoh: kualitas saat operasi penyembuhan penyakit.

2. Functional Quality, yaitu komponen yang berkaitan dengan kualitas cara penyampaian suatu jasa.

3. Corporate Image, yaitu profil, reputasi, citra umum, dan daya tarik khusus suatu perusahaan. 
Parasuraman, et al (1990) mengembangkan model ServQual atau Service Quality sebagai model untuk membantu menganalisis penyebab masalah kualitas dan cara-cara melakukan perbaikan kualitas. Model ini merupakan model kualitas jasa yang paling populer dan hingga kini banyak dijadikan acuan dalam riset manajamen dan pemasaran jasa. Model Servqual digambarkan pada gambar 1 berikut :

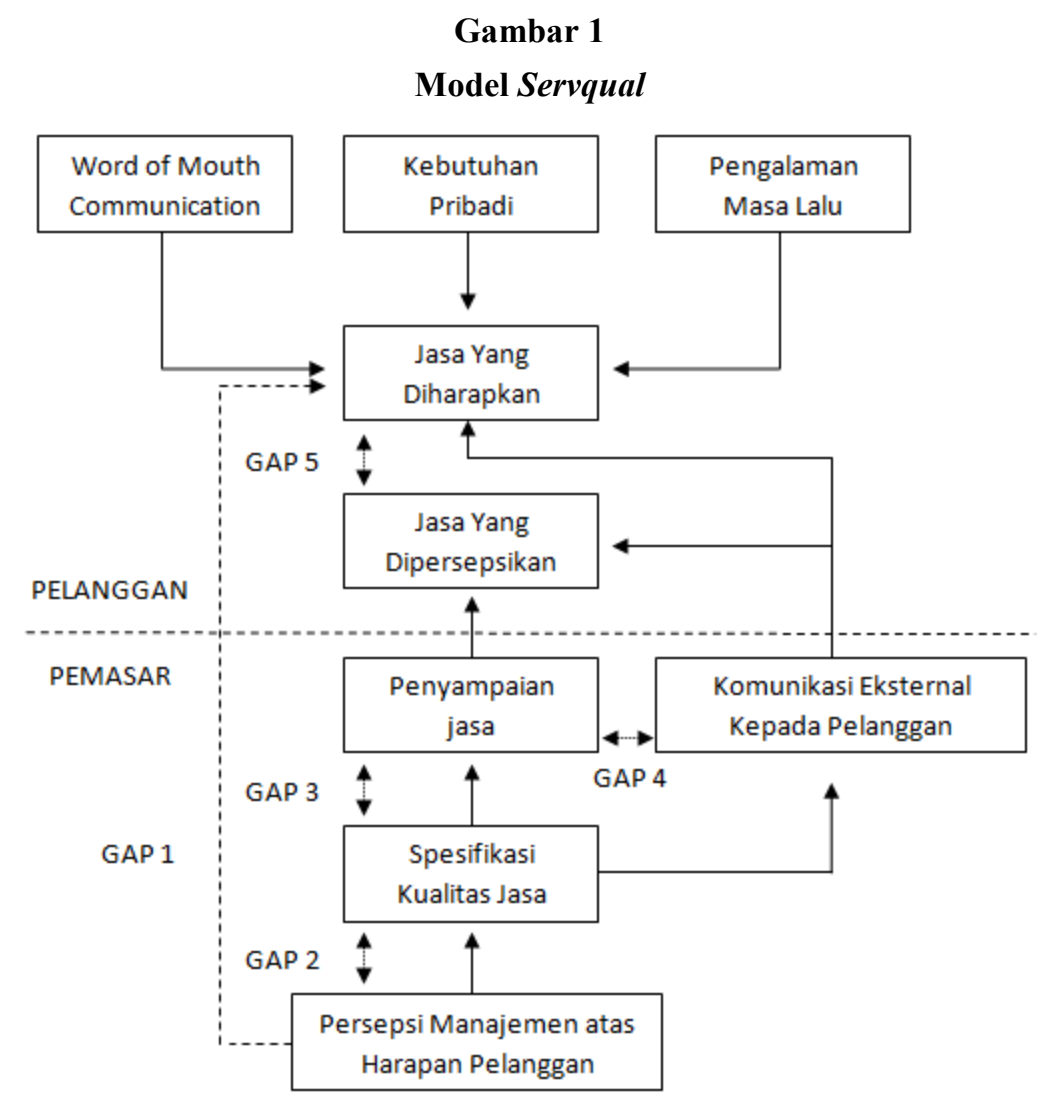

Sumber: Parasuraman. (Journal of Marketing vol.49, Fall 1985)

Terlihat dari gambar 1 bahwa terdapat lima gap penting yang menjadi perhatian, lima gap utama yang terangkum dalam gambar diatas meliputi :

1. GAP 1, Gap antara harapan pelanggan dan persepsi perusahaan (knowledge gap).

Gap ini berarti, bahwa pihak perusahaan mempersepsikan bahwa ekspektasi pelanggan terhadap kualitas jasa secara tidak akurat. Beberapa kemungkinan penyebabnya antara lain : informasi yang didapatkan dari lapangan dan analisis permintaan kurang akurat, interpretasi yang kurang akurat atas informasi ekspektasi pelanggan, tidak adanya analisis permintaan, buruknya atau tiadanya aliran informasi ke atas dari staf kontak pelanggan ke pihak perusahaan, dan terlalu banyak jenjang manajerial yang menghambat atau mengubah informasi yang disampaikan dari karyawan kontak pelanggan ke pihak perusahaan. Sebagai contoh, pihak perusahaan mungkin saja mengira bahwa pelanggannya lebih mengutamakan ketepatan waktu pengisian bahan bakar, padahal mereka lebih mementingkan akurasi dan ketepatan dalam jumlah pengisian. 
2. GAP 2, Gap antara persepsi perusahaan terhadap harapan konsumen dan spesifikasi kualitas jasa (standards gap).

Gap ini berarti antara spesifikasi kualitas pelayanan tidak konsisten dengan persepsi perusahaan terhadap ekspektasi kualitas. Penyebabnya antara lain : tidak adanya standar kinerja yang jelas, kesalahan perencanaan atau prosedur perencanaan yang tidak memadai, manajemen perencanaan yang buruk, kurangnya penetapan tujuan yang jelas dalam organisasi, kurangnya dukungan dan komitmen manajemen puncak terhadap perencanaan kualitas pelayanan, kekurangan sumber daya, dan situasi permintaan berlebihan. Contohnya pihak perusahaan meminta para karyawannya agar melayani pelanggan dengan "cepat" tanpa merinci standart waktu pelayanan yang bisa dikategorikan cepat.

3. GAB 3, Gap antara spesifikasi kualitas jasa serta penyampaian jasa (delivery gap).

Gap ini berarti bahwa spesifikasi kualitas tidak terpenuhi oleh kinerja dalam proses produksi dan penyampaian jasa. Sejumlah penyebabnya antara lain : spesifikasi kualitas terlalu rumit atau terlalu kaku, para karyawan tidak menyepakati spesifikasi tersebut dan karenanya tidak memenuhinya, spesifikasi tidak sejalan dengan budaya korporat yang ada, manajemen operasi pelayanan yang buruk, kurang memadainya aktifitas internal marketing, serta teknologi dan sistem yang ada tidak memfasilitasi kinerja sesuai dengan spesifikasi. Kurang terlatihnya karyawan, beban kerja terlampau berlebihan, dan standar kinerja tidak dapat dipenuhi karyawan (terlalu tinggi atau tidak realistis) juga bisa menyebabkan tejadinya gap ini. Selain itu mungkin pula karyawan dihadapkan pada standar - standar yang saling bertentangan satu sama lain. Sebagai contoh, para karyawan SPBU diwajibkan untuk melayani pelanggan dengan jangka waktu yang cepat, tetapi di saat bersamaan, mereka juga harus tetap menjaga akurasi dan ketepatan jumlah pengisian serta melayani keluhan pelanggan.

4. GAP 4, Gap antara penyampaian jasa dan komunikasi serta interaksi eksternal (communications gap). Gap ini berarti bahwa janji - janji yang disampaikan melalui aktifitas komunikasi dan interaksi perusahaan tidak konsisten dengan pelayanan yang disampaikan kepada pelanggan. Hal ini bisa disebabkan oleh beberapa faktor, yaitu perencanaan komunikasi dengan pelanggan tidak terintegrasi dengan operasi jasa, kurangnya koordinasi antara pemasaran eksternal dan operasi jasa, organisasi gagal memenuhi spesifikasi yang ditetapkannya, sementara kampaye komunikasi dalam sosialisasi pemasaran sesuai dengan spesifikasi tersebut, dan kecenderungan untuk melakukan "over - promised, under deliver". Iklan dan slogan janji perusahaan sering mempengaruhi ekspektasi pelanggan. Jika pihak perusahaan memberikan janji berlebihan, maka resikonya adalah harapan pelanggan bisa membumbung tinggi dan sulit dipenuhi. Contohnya, pelanggan akan merasa kecewa apabila kualitas produk yang telah mereka gunakan tidak sebaik atau sebagus yang digambarkan atau yang dijanjikan.

5. GAP 5, Gap antara jasa yang dipersepsikan dan jasa yang diharapkan (service gap).

Gap ini berarti bahwa jasa yang dipersepsikan tidak konsisten dengan jasa yang diharapkan. Gap ini bisa menimbulkan sejumlah konsekuensi negatif, seperti kualitas buruk dan masalah kualitas, komunikasi gethok tular yang negatif, dampak negatif terhadap citra korporat atau citra lokal, dan kehilangan pelanggan. Gap ini terjadi apabila pelanggan mengukur kinerja atau prestasi perusahaan berdasarkan kriteria yang berbeda, atau bisa juga mereka keliru menginterpretasikan kualitas jasa yang bersangkutan. 
Harapan konsumen terhadap layanan merupakan keinginan atau permintaan ideal konsumen terhadap layanan yang akan diberikan oleh penyedia layanan. Harapan konsumen harus menjadi acuan bagi penyedia layanan untuk mendesain, menghasilkan dan menyampaikan layanan kepada konsumen. Seperti yang terlihat pada gambar berikut:

\section{Gambar 2}

\section{Model kepuasan pelanggan menurut} Berry dan Parasuraman

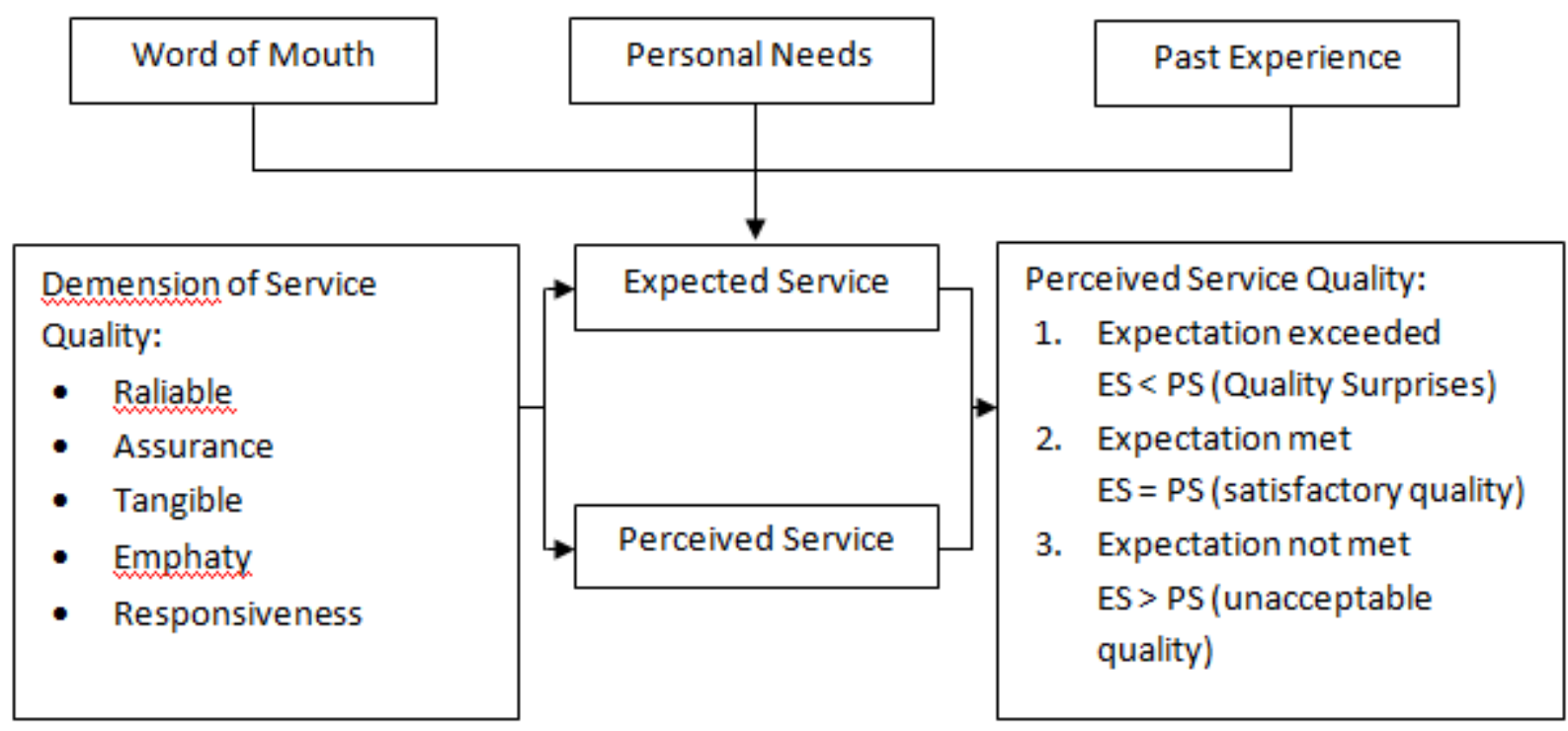

Sumber: Parasuraman. (Journal of Marketing vol.49, Fall 1985)

Gambar dari Perceived Service Quality (kualitas layanan yang diharapkan) diatas memberikan gambaran bahwa pada dasarnya dipengaruhi oleh faktor berikut ini:

1. Komunikasi antara mulut ke mulut (word of mouth)

2. Kebutuhan individu konsumen (personal needs)

3. Pengalaman yang dirasakan oleh konsumen pada masa lalu (past experience).

Sementara itu, menurut hasil identifikasi Parasuraman, Zeithaml \& Berry (1985) ada sepuluh faktor utama yang menentukan kualitas jasa, yaitu:

1. Reliability, mencakup dua hal pokok yaitu konsistensi kinerja (performance) dan kemampuan untuk dipercaya (dependabelity). Artinya perusahaan memberikan jasanya secara tepat semenjak saat pertama dan sesuai dengan janjinya (memnuhi janji).

2. Responsiveness, yaitu kemauan atau kesiapan para karyawan untuk memberikan jasa yang dibutuhkan pelanggan.

3. Competence, yaitu setiap orang memiliki ketrampilan dan pengetahuan yang dibutuhkan agar dapat memberikan jasa/pelayanan tertentu. 
4. Access, yaitu meliputi kemudahan untuk dihubungi dan ditemui. Ini mencakup lokasi fasilitas jasa yang mudah dijangkau, waktu menunggu yang tidak terlalu lama, saluran komunikasi yang mudah dihubungi.

5. Courtesy, yaitu meliputi sikap sopan santun, respek, perhatian, dan keramah-tamahan para contact personals.

6. Communication, yaitu memberikan informasi kepada pelanggan dalam bahasa yang dapat mereka pahami, serta selalu mendengarkan saran dan keluhan pelanggan.

7. Credibility, yaitu sifat jujur dan dapat dipercaya. Ini mencakup nama perusahaan, reputasi perusahaan, dan karakteristik pribadi para contact personnels.

8. Security, yaitu aman dari bahaya, risiko, atau keragu-raguan. Ini mencakup keamanan secara fisik, keamanan finansial, dan kerahasiaan.

9. Understanding/Knowing the customer, yaitu usaha untuk memahami kebutuhan peanggan.

10. Tangibles, yaitu bukti fisik dari jasa. Ini dapat berup fasilitas fisik, peralatan yang dipergunakan, atau representatif fisik dari jasa (contoh: kartu kredit)

Selanjutnya Bery \& Parasuraman melakukan agregasi dari 10 menjadi 5 dengan akronim RATER, dengan kata lain Metode SERVQUAL membagi kualitas pelayanan ke dalam lima dimensi kualitas layanan yang dikembangkan oleh Parasuraman et.al, yaitu (Tjiptono, 2000):

1. Reliability (keandalan), yaitu kemampuan memberikan pelayanan yang dijanjikan dengan segera, akurat, dan memuaskan.

2. Assurance (jaminan), yaitu mencakup pengetahuan, kemampuan, kesopanan, dan sifat dapat dipercaya yang dimiliki para staf sehingga para pelanggan bebas dari bahaya, resiko dan keragu-raguan.

3. Tangible (bukti langsung), yaitu meliputi fasilitas fisik, perlengkapan, pegawai, dan sarana komunikasi.

4. Empaty (empati), yaitu meliputi kemudahan dalam melakukan hubungan, komunikasi yang baik, perhatian pribadi, dan keinginan untuk memahami kebutuhan para pelanggan.

5. Responsiveness (tanggung jawab), yaitu keinginan para staf untuk membantu para pelanggan dan memberikan pelayanan dengan tanggap.

\section{METODE PENELITIAN}

Hal-hal yang terkait dalam metode penelitian ini adalah sebagai berikut:

1. Jenis Penelitian

Jenis penelitian ini bersifat penelitian deskriptif kuantitatif dengan menggunakan metode Servqual (Service Quality), dimana metode ini menganalisa hasil kuisioner yang berisikan skala likert $1-5$ dan informasi sekunder pendukung lainnya.

2. Tempat dan Waktu Penelitian

Adapun lokasi penelitian ini adalah di Puskesmas Parit Haji Husein II Pontianak. Sedangkan waktu penelitiannya selama 6 bulan dari bulan April sampai dengan bulan September 2016.

3. Populasi dan Sample Penelitian 
Populasi penelitian ini adalah pengunjung/pasien puskesmas rawat jalan pada dokter umum di Puskesmas Parit Haji Husein II Pontianak. Sedangkan teknik pengambilan samplenya mengunakan Purposive Random Sampling.

4. Instrumen Penelitian

a. Panduan observasi

b. Alat dokumentasi

c. Menyusun pertanyaan untuk mengukur atribut. Untuk mengukurnya akan dibuat instrumen survei dalam bentuk kuesioner. Ada dua macam kuisioner yang dibuat yaitu:

1. Kuesioner harapan pasien berisi tentang penilaian pasien terhadap harapan layanan yang ingin diterima.

2. Kuesioner realitas/kenyataan layanan berisi tentang penilaian pasien terhadap kondisi layanan yang diterima saat ini.

\section{Teknik Pengumpulan Data}

a. Kuesioner

Pengumpulan data dengan model skala likert, dimana data yang diperlukan adalah harapan dan realitas layanan yang diterima oleh pengunjung/pasien rawat jalan pada dokter umum di Puskesmas Parit Haji Hesein II Pontianak.

b. Dokumentasi

Informasi pendukung lainnya seperti fasilitas pendukung pelayanan kepada pasien.

6. Alat Analisis Data

Data dari hasil kuisioner kemudian diolah dan dimasukkan ke dalam diagram kartesius yang di seting dari program SPSS. Lebih jelas mengenai gambarannya adalah seperti berikut:

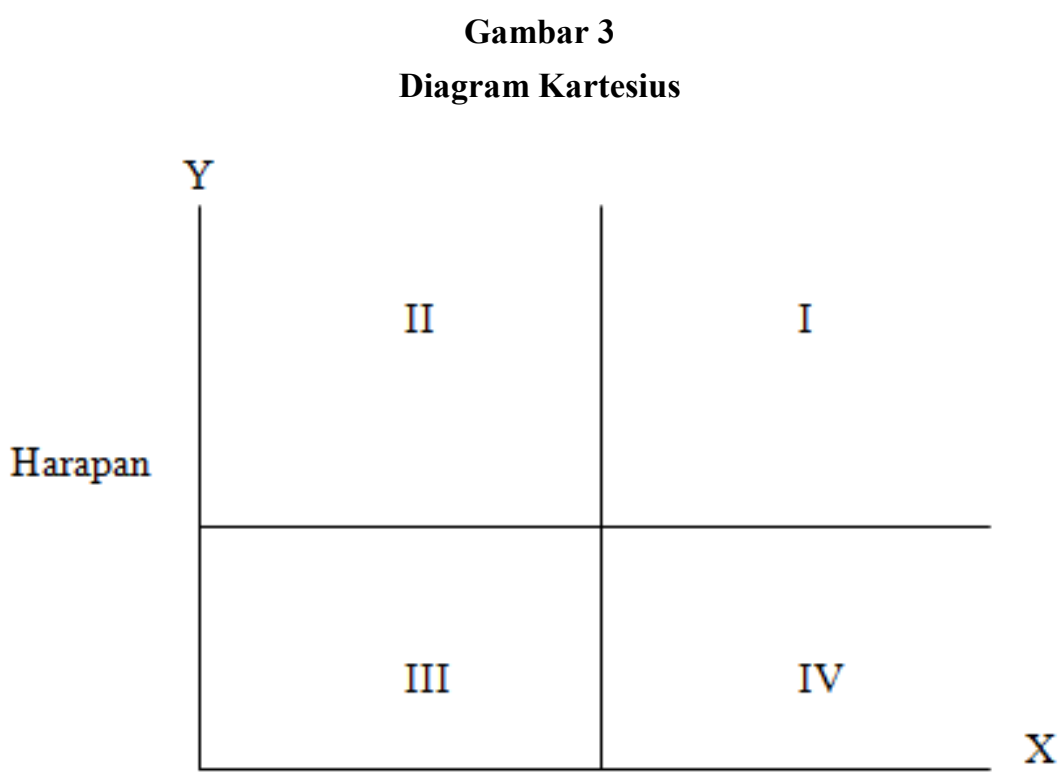

Realitas

Sumber: Freddy Rangkuti (2003:110) 
Diagram kartesius memiliki empat posisi kuadran yang memiliki makna pada setiap posisinya, selengkapnya sebagai berikut:

a. Kuadran I : posisi disini adalah posisi layanan dimana perusahaan harus mempertahankannya.

b. Kuadran II : posisi disini adalah posisi layanan yang dianggap sangat penting dan diharapkan oleh konsumen, kinerjanya kurang bagus sehingga kurang memuaskan konsumen.

c. Kuadrant III : posisi disini adalah posisi yang tidak terlalu perlu diperhatikan karena di posisi ini bukan sesuatu yang diharapkan oleh konsumen. Dengan kata lain tidak menjadi persoalan bagi perusahaan meskipun kinerjanya tidak bagus, karena bukan sesuatu yang diharapkan oleh mahasiswa.

d. Kuadran IV : posisi disini adalah posisi dimana hal berlebihan muncul, dan perusahaan perlu mengendalikan karena disini apa yang dianggap tidak penting bagi konsumen, justru berkinerja bagus.

\section{HASIL PENELITIAN}

Parasuraman, et al (1990) mengembangkan model ServQual atau Service Quality sebagai model untuk membantu menganalisis penyebab masalah kualitas dan cara-cara melakukan perbaikan kualitas. Model ini merupakan model kualitas jasa yang paling populer dan hingga kini banyak dijadikan acuan dalam riset manajamen dan pemasaran jasa. Konsep ServQual memaparkan tentang 5 konsep utama dalam pengukuran pelayanan yaitu Reliable, Assurance, Tangible, Emphaty, dan Responsiveness.

Seperti dalam kuesioner yang telah peneliti lampirkan pada lampiran tabel 1, bahwa terdapat 25 item pertanyaan untuk mengurai konsep Parasuraman, et al (1990) tentang Service Quality yaitu; Reliable, Assurance, Tangible, Emphaty, dan Responsiveness. Penyebaran item pertanyaan pada konsep diatas yaitu 5 pertanyaan untuk Reliable, 5 pertanyaan untuk Assurance, 5 pertanyaan untuk Tangible, 5 pertanyaan untuk Emphaty, dan 5 pertanyaan untuk Responsiveness, sehingga total menjadi 25 pertanyaan (Questions) yang peneliti singkat menjadi "Q". Selanjutnya Q1 s/d Q5 adalah item pertanyaan untuk "Reliable", Q6 s/d Q10 adalah item pertanyaan untuk "Assurance", Q11 s/d Q15 adalah item pertanyaan untuk "Tangible", Q16 s/d Q20 adalah item pertanyaan untuk "Emphaty", dan Q21 s/d Q25 adalah item pertanyaan untuk "Responsiveness". Kemudian ke-25 pertanyaan diatas ditanyakan kepada 50 responden yang sedang berobat di klinik umum Puskesmas Parit Haji Husein 2 Pontianak selama lebih kurang 5-6 bulan. Hasil penelitian dari 50 responden bisa dilihat pada lampiran tabel 2 .

Berdasarkan pada hasil analisis yang terlampir pada tabel 3, bahwa yang masuk ke kuadran I pada diagram kartesius adalah Q3 = Diagnosa dokter tepat dan Akurat, Q4 = Perhatian kepuasan pasien, Q6 = Kecakapan pegawai dalam melayani, Q7 = Kesopanan pelayanan, $\quad$ Q8 $=$ Analisis Dokter yg tidak meragukan, Q9 = Analisis Dokter tidak beresiko, Q10 = Dokter dapat dipercaya, Q16 = Mudah berkonsultasi dengan dokter dan pegawai, Q17 = Tidak ada hambatan konsultasi dengan dokter, Q18 = Dokter memberi info dengan detail, Q19 = Dokter minta info ke pasien tentang keluhan, Q22 = Dokter cepat tanggap, Q23 = Diagnosa Dokter dapat dipertanggung jawabkan, Q24 = Dokter mendengarkan keluhan dengan baik, Q25 = Dokter melayani pasien selama jam kerja. Sedangkan hasil analisis yang terlampir pada tabel 4, bahwa yang masuk ke kuadran II yaitu Q5 = Kesesuaian jadwal buka dan tutup. Dan hasil analisis yang terlampir pada tabel 5, bahwa yang masuk ke kuadran III adalah Q1 = Kecepatan pelayanan, Q2 = Pegawai datang tepat waktu, Q11 
= Bentuk fisik puskesmas bagus, Q12 = Fasilitas puskesmas lengkap, Q13 = Pegawai siap di meja, Q14 = Sarana teknologi sudah baik, Q15 = Kursi ruang tunggu memadai. Sedangkan hasil analisis yang terlampir pada tabel 6, bahwa yang masuk ke kuadran IV adalah Q20 = Dokter dan pegawai memberikan arahan dengan baik dan Q21 = Petugas menyapa kepada pengunjung yang bingung.

\section{PEMBAHASAN PENELITIAN}

Jenis pelayanan yang masuk pada Kuadran I adalah semua jenis layanan yang harus dipertahankan oleh pihak Puskesmas Parit Haji Husein II Pontianak, dengan kata lain bahwa jenis layanan di Kuadran ini sudah termasuk kategori baik. Jenis layanan tersebut adalah : $\quad$ Q3 = Diagnosa dokter tepat dan Akurat, Q4 = Perhatian kepuasan pasien, Q6 = Kecakapan pegawai dalam melayani, Q7 = Kesopanan pelayanan, Q8 = Analisis Dokter yg tidak meragukan, Q9 = Analisis Dokter tidak beresiko, Q10 = Dokter dapat dipercaya, Q16 = Mudah berkonsultasi dengan dokter dan pegawai, Q17 = Tidak ada hambatan konsultasi dengan dokter, Q18 $=$ Dokter memberi info dengan detail, Q19 = Dokter minta info ke pasien tentang keluhan, Q22 = Dokter cepat tanggap, Q23 = Diagnosa Dokter dapat dipertanggung jawabkan, Q24 = Dokter mendengarkan keluhan dengan baik, Q25 = Dokter melayani pasien selama jam kerja.

Jenis pelayanan yang masuk pada Kuadran II adalah semua jenis layanan yang sangat diharapkan oleh pasien Puskesmas Parit Haji Husein II Pontianak. Sehingga jenis pelayanan ini yang harus diperjuangkan agar menjadi baik oleh pihak Puskesmas. Jenis pelayanan tersebut adalah : Q5 = Kesesuaian jadwal buka dan tutup. Jenis pelayanan yang masuk pada Kuadran III adalah semua jenis layanan yang tidak terlalu diharapkan oleh pasien. Dengan kata lain bahwa pihak Puskesmas tidak perlu risau dengan pelayanan yang ada pada kuadran ini, karena pasien tidak terlalu memperdulikannya. Jenis palayanan tersebut adalah : Q1 = Kecepatan pelayanan, Q2 = Pegawai datang tepat waktu, Q11 = Bentuk fisik puskesmas bagus, Q12 = Fasilitas puskesmas lengkap, Q13 = Pegawai siap di meja, Q14 = Sarana teknologi sudah baik, Q15 = Kursi ruang tunggu memadai.

Jenis pelayanan yang masuk pada Kuadran IV adalah semua jenis layanan yang berlebihan muncul.yaitu pelayanan yang menurut pasien tidak terlalu penting, malah berkinerja baik. Jenis pelayanan tersebut adalah : Q20 = Dokter dan pegawai memberikan arahan dengan baik dan Q21 = Petugas menyapa kepada pengunjung yang bingung.

\section{KESIMPULAN DAN SARAN}

Berdasarkan hasil penelitian layanan pasien Puskesmas Paris II Pontianak, peneliti berkesimpulan bahwa pihak Puskesmas telah banyak berhasil memberikan pelayanan yang maksimal kepada pengunjung/ pasiennya. Hal ini terbukti pada lampiran tabel 7 bahwa sebanyak $60 \%$ layanan telah berkinerja dengan baik. Jenis pelayanan tersebut adalah yang masuk pada Kuadran I Diagram Kartesius, layanan ini harus dijaga dan dipertahankan. Layanan tersebut adalah : $\quad$ Q3 = Diagnosa dokter tepat dan Akurat, Q4 = Perhatian kepuasan pasien, Q6 = Kecakapan pegawai dalam melayani, Q7 = Kesopanan pelayanan, Q8 = Analisis Dokter yg tidak meragukan, Q9 = Analisis Dokter tidak beresiko, Q10 = Dokter dapat dipercaya, Q16 = Mudah berkonsultasi dengan dokter dan pegawai, Q17 = Tidak ada hambatan konsultasi dengan dokter, Q18 = Dokter memberi info dengan detail, Q19 = Dokter minta info ke pasien tentang keluhan, Q22 = Dokter cepat tanggap, Q23 = 
Diagnosa Dokter dapat dipertanggung jawabkan, Q24 = Dokter mendengarkan keluhan dengan baik, Q25 = Dokter melayani pasien selama jam kerja.

Sedangkan saran untuk kinerja layanan di Puskesmas Parit Haji Husein II Pontianak adalah menyikapi jenis pelayanan yang ada pada Kuadran II Diagram Kartesius. Karena ini yang menurut responden/pasien kurang berkinerja baik yaitu masalah Q5 = kesesuaian jam buka dan jam tutup palayanan. Bisa jadi disiplin ketepatan waktu kerja yang perlu diperhatikan. Dan untungnya pekerjaan rumah untuk memperbaiki layanan di puskesmas ini sedikit, yaitu hanya satu layanan saja yang berada di kuadran II ini. Hal ini terlihat pada lampiran tabel 7 yaitu hanya sebesar 4 \% saja. Dan satu hal lagi yang perlu diperhatikan lagi adalah layanan yang ada pada Kuadran IV, karena layanan ini terlalu berlebihan. Jadi bisa juga sedikit dikurangi agar lebih menghemat biaya dan waktu dan dapat berfokus pada peningkatan layanan pada Kuadran II Diagram kartesius. Layanan tersebut adalah : Q20 = Dokter dan pegawai memberikan arahan dengan baik dan Q21 = Petugas menyapa kepada pengunjung yang bingung. Dan untungnya pada diagram IV ini juga sedikit yaitu sebesar $8 \%$ saja, seperti yang terlihat pada lampiran tabel 7 .

\section{DAFTAR PUSTAKA}

Kotler, P.1997. Marketing Management: Analysis, Planning, Implementation, and control. (ninth Edition).

New Jersey: Prentice Hall International,Inc.

Rangkuti, Freddy. 2003. Measuring Custommer Satisfaction. Jakarta: PT. Gramedia Pustaka.

Simamora, Bilson. 2004. Panduan Riset Perilaku Konsumen. Jakarta: PT. Gramedia Pustaka.

Singarimbun, Masri. 1989. Metode Penelitian Survei. Jakarta: LP3ES.

Supangat, Andi. 2007. Statistika: dalam Kajian Deskriptif, Inferensia, dan Non Parametrik. Jakarta:

Kencana Prenada Media Group.

Tjiptono, F.1996. Manajemen Jasa. Yogyakarta: Andi Offset.

\section{Literatur Jurnal \& Majalah}

Parasuraman, A.Zeithaml, V.A., \& Berry, L.L.1985. A Conceptual Model of Service Quality \& Its Implicator

Future Research. Journal of Marketing Vol. 49 (Fall 1985).

Rodhiah.1997. Pasar lobal dalam Prespektif Kepuasan Pelanggan. Usahawan No.06 TH. XXVI.

Supranto, J. 1996. Pengukuran Tingkat Kepuasan Pelanggan. Usahawan No. 04 TH XXV.

Universitas Terbuka.2003. Tingkat Kepuasan Mahasiswa terhadap Pelayanan universitas Terbuka. Jurnal Pendidikan Terbuka dan Jarak Jauh. Vol.4 No.2 Jakarta 


\section{Lampiran}

Tabel 1. Item Pertanyaan

\begin{tabular}{|l|l|}
\hline \multicolumn{2}{|c|}{ Questions (Q) dan Materi Pertanyaan } \\
\hline Q1 = Kecepatan pelayanan & Q16 = Mudah berkonsultasi dengan dokter dan pegawai \\
Q2 = Pegawai datang tepat waktu & Q17 = Tidak ada hambatan konsultasi dengan dokter \\
Q3 = Diagnosa dokter tepat dan Akurat & Q18 = Dokter bemberi info dengan detail \\
Q4 = Perhatian kepuasan pasien & Q19= Dokter minta info ke pasien tentang keluhan \\
Q5 = Kesesuaian jadwal buka dan tutup & Q20= Dokter dan pegawai memberikan arahan dengan baik \\
Q6 = Kecakapan pegawai dalam melayani & Q21 = Petugas menyapa kepada yang bingung \\
Q7 = Kesopanan pelayanan & Q22= Dokter cepat tanggap \\
Q8 = Analisis Dokter yg tidak meragukan & Q23 = Diagnosa Dokter dapat dipertanggung jawabkan \\
Q9 = Analisis Dokter tidak beresiko & Q24= Dokter mendengarkan keluhan dengan baik \\
Q10= Dokter dapat dipercaya & Q25 = Dokter melayani pasien selama jam kerja \\
Q11 = Bentuk fisik puskesmas bagus & \\
Q12= Fasilitas puskesmas lengkap & \\
Q13 = Pegawai siap di meja & \\
Q14= Sarana teknologi sudah baik & \\
Q15= Kursi ruang tunggu memadai & \\
\hline
\end{tabular}

Sumber: Data diolah 
Tabel 2. Hasil Penghitungan Rata-Rata Harapan dan Realita

\begin{tabular}{|l|r|r|}
\hline \multicolumn{3}{|c|}{ Questions (Q) dan Hasil Rata-Rata } \\
\hline Questions & Rata-Rata Harapan & Rata-Rata Realita \\
\hline Q1 & 4.76 & 3.78 \\
\hline Q2 & 4.72 & 3.76 \\
\hline Q3 & 4.84 & 4.00 \\
\hline Q4 & 4.84 & 4.04 \\
\hline Q5 & 4.88 & 3.74 \\
\hline Q6 & 4.88 & 4.10 \\
\hline Q7 & 4.84 & 4.28 \\
\hline Q8 & 4.92 & 3.98 \\
\hline Q9 & 4.94 & 4.02 \\
\hline Q10 & 4.88 & 4.02 \\
\hline Q11 & 4.48 & 3.56 \\
\hline Q12 & 4.62 & 3.36 \\
\hline Q13 & 4.72 & 3.88 \\
\hline Q14 & 4.44 & 3.44 \\
\hline Q15 & 4.56 & 3.62 \\
\hline Q16 & 4.86 & 4.14 \\
\hline Q17 & 4.82 & 4.12 \\
\hline Q18 & 4.84 & 4.04 \\
\hline Q19 & 4.84 & 4.14 \\
\hline Q20 & 4.72 & 4.10 \\
\hline Q21 & 4.60 & 3.96 \\
\hline Q22 & 4.80 & 4.04 \\
\hline Q23 & 4.94 & 4.02 \\
\hline Q24 & 4.90 & 4.16 \\
\hline Q25 & 4.84 & 4.10 \\
\hline
\end{tabular}

Sumber: Data diolah 


\section{Gambar 1. Penyebaran Hasil Data Harapan dan Realita}

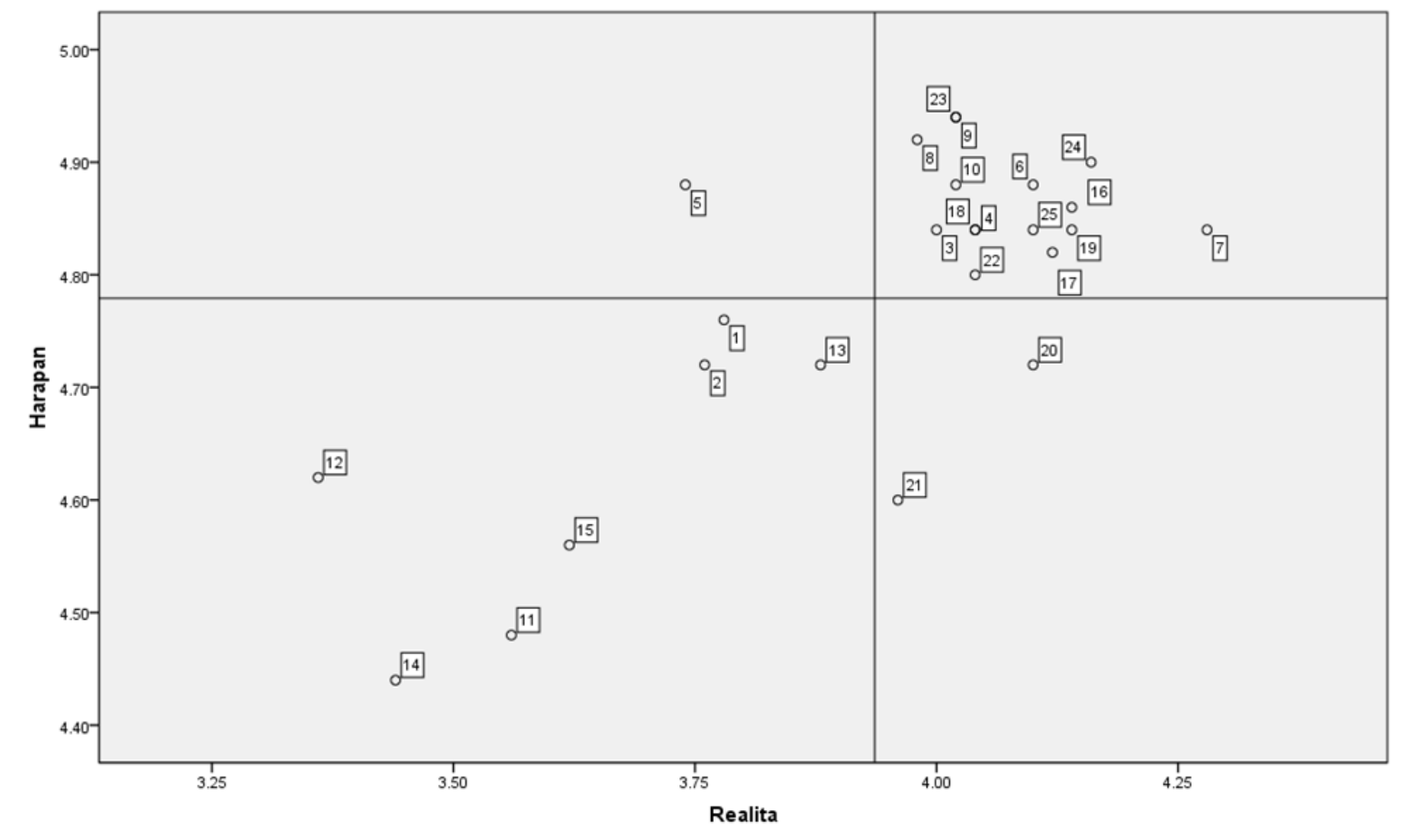

\section{Tabel 3. Hasil Kuadran I}

\begin{tabular}{|l|}
\hline \multicolumn{1}{|c|}{ Questions (Q) dan Materi Pertanyaan } \\
\hline Q3 = Diagnosa dokter tepat dan Akurat \\
Q4 = Perhatian kepuasan pasien \\
Q6 = Kecakapan pegawai dalam melayani \\
Q7 = Kesopanan pelayanan \\
Q8 = Analisis Dokter yg tidak meragukan \\
Q9 = Analisis Dokter tidak beresiko \\
Q10= Dokter dapat dipercaya \\
Q16 = Mudah berkonsultasi dengan dokter dan pegawai \\
Q17 = Tidak ada hambatan konsultasi dengan dokter \\
Q18 = Dokter memberi info dengan detail \\
Q19 = Dokter minta info ke pasien tentang keluhan \\
Q22 = Dokter cepat tanggap \\
Q23 = Diagnosa Dokter dapat dipertanggung jawabkan \\
Q24 = Dokter mendengarkan keluhan dengan baik \\
Q25 = Dokter melayani pasien selama jam kerja \\
\end{tabular}

Sumber: Data diolah 


\section{Tabel 4. Kuadran II}

\begin{tabular}{|c|}
\hline Questions (Q) dan Materi Pertanyaan \\
\hline Q5 = Kesesuaian jadwal buka dan tutup \\
\hline
\end{tabular}

Sumber: Data diolah

\section{Tabel 5. Hasil Kuadran III}

\begin{tabular}{|l|}
\hline \multicolumn{1}{|c|}{ Questions (Q) dan Materi Pertanyaan } \\
\hline $\mathrm{Q} 1=$ Kecepatan pelayanan \\
$\mathrm{Q} 11=$ Pegawai datang tepat waktu \\
$\mathrm{Q} 12$ = Fasilitas puskesmas lengkap \\
$\mathrm{Q} 13=$ Pegawai siap di meja \\
$\mathrm{Q} 14=$ Sarana teknologi sudah baik \\
$\mathrm{Q} 15=$ Kursi ruang tunggu memadai
\end{tabular}

Sumber: Data diolah

\section{Tabel 6. Hasil Kuadran IV}

\begin{tabular}{|c|}
\hline Questions (Q) dan Materi Pertanyaan \\
\hline Q20 = Dokter dan pegawai memberikan arahan dengan baik \\
Q21 = Petugas menyapa kepada yang bingung \\
\hline
\end{tabular}

Sumber: Data diolah 
Tabel 7. Prosentase Distribusi Item Pertanyaan (Q)

\begin{tabular}{|l|l|l|l|}
\hline No & Kuadran & Jumlah Item Pertanyaan (Q) & Prosentase \\
\hline 1. & Kuadran I & 15 Item Q & $60 \%$ \\
\hline 2. & Kuadran II & 1 Item Q & $4 \%$ \\
\hline 3. & Kuadran III & 7 Item Q & $28 \%$ \\
\hline 4. & Kuadran IV & 2 Item Q & $8 \%$ \\
\hline & TOTAL & 25 Pertanyaan (Q) & $100 \%$ \\
\hline
\end{tabular}

Sumber: Data diolah 